\title{
Assessment of influence of pro-health nutrition education and resulting changes of nutrition behavior of women aged 65-85 on their body content
}

\author{
Mariola Friedrich, Zuzanna Goluch-Koniuszy \\ Department of Human Nutrition Physiology, Faculty of Food Sciences and Fisheries, Western Pomeranian University of Technology \\ in Szczecin, Poland
}

\begin{abstract}
Introduction: One of systemic changes connected to body ageing is the change of body content and the possibility of formation and/or intensification of insulin resistance, dyslipidemia and hypertension symptoms.

Material and methods: The research was conducted on 68 women aged 65-85 with body mass index (BMI) of 25.3 to $44.5 \mathrm{~kg} / \mathrm{m}^{2}$ who have been educated for four months. The energy and nutritive value of 204 daily food rations (DFRs) was evaluated twice: first days of October and - after the diet correction and implementation of the basic rules - from the end of January. The measurements, anthropometric and body content (in 35 women under research) with the bio-impedance method was checked twice - before and after completing the education.

Results: After completing the education, there was a statistically significant increase in consumption of grain products, fermented milk products, potatoes, fruit and vegetables, as well as seeds of legumes. Consumption of meat and cold meats, sugar and sweets significantly decreased. In the course of education, an individualspecific decrease in body mass of the participants was noticed, which found its reflection in positive changes of the anthropometric indicators value. A significant decrease in fat content in bodies of women under research was also noticed, which was accompanied by a slight increase in fat-free body mass and water.

Conclusions: The four-month pro-health education of women influenced changes in improper nutrition habits resulting in, besides the improvement of organism functions and well-being of women under research, body mass loss and changes in content of the body.
\end{abstract}

Key words: women, bio-impedance, nutritional status, nutrition manner, nutrition education.

\section{Introduction}

Current results of research provide the elderly age, in spite of the physiological process of organism ageing, does not have to be connected with illness and/or becoming decrepit. One of general body changes connected with ageing is the change in body content. After the age of 40 and in subsequent years, we can observe the lowering of fat-free body mass, mineral content and bone mineral density, while in women, the index of lowering bone mass is higher than the index of lowering of fat-free body mass content. These changes are accompanied simultaneously by, also related to age, an increase in fat tissue content, including visceral fat [1]. The effects of body content change, even these resulting from natural ageing are not only lowered efficiency of the organism but first of all, possibility of forming and/or intensifying symptoms of insulin resistance, dyslipidemia and hypertension [2]. One method which has a significant impact on change in body composition and to improve blood parameters in patients with body mass index $(\mathrm{BMI}) \geq 35 \mathrm{~kg} / \mathrm{m}^{2}$ is to perform a bariatric surgery [3].

However, an original author's program of prohealth nutrition education for menopausal women has been implemented for many years; the program, by influencing their nutritional behaviors, brought many beneficial and pro-health effects including a beneficial change in body content and content of visceral fat [46]. This is why it was decided to check whether and how much similar education providing information and recommendations adapted to perception abilities and organism needs, would influence the nutrition behaviors and what is more, pro-health effects on elderly women.

The possibility of such education and making changes in nutrition methods by women aged 65-85 was confirmed by the results of earlier research. A beneficiary influence on the body mass and blood parameters value, determined in medicine as diagnostic [7], was also determined. The problem of what influence 
the correction of diet conducted this way has on body content and location of the lost fat tissue was left open.

\section{Material and methods}

The research was conducted with the participation of 68 women aged 65-85 (average age: 70.2 years), with $\mathrm{BMI}$ from 25.3 to 44.5 ; the women are members of the Association of Third Age University (ATAU), taking part in original authors' educational program "Nutrition in Elderly Age - How to Be Healthy, Fit and... Slimmer" cofinanced by the Department of Health and Social Policies of the City Hall of Szczecin (WZiPS-IV/MG/08/10

Tab. I. Socioeconomic characteristics of the examined women aged $65-85$ years $(n=68)$

\begin{tabular}{|c|c|}
\hline Socioeconomic characteristics & Women (\%) \\
\hline \multicolumn{2}{|l|}{ Marital status } \\
\hline Single & 5.9 \\
\hline Married & 36.8 \\
\hline Widow & 52.9 \\
\hline Divorced & 4.4 \\
\hline \multicolumn{2}{|l|}{ Number of children } \\
\hline None & 7.4 \\
\hline 1 & 50.0 \\
\hline 2 & 35.2 \\
\hline$>2$ & 7.4 \\
\hline \multicolumn{2}{|l|}{ Education } \\
\hline Secondary school & 68.0 \\
\hline University degree & 32.0 \\
\hline \multicolumn{2}{|l|}{ Type of work before retirement } \\
\hline Manual work & 19.1 \\
\hline White-collar work & 80.9 \\
\hline \multicolumn{2}{|l|}{ Period of retirement } \\
\hline 5 years & 11.8 \\
\hline 6-10 years & 33.8 \\
\hline $10-15$ years & 38.2 \\
\hline$>15$ years & 16.2 \\
\hline \multicolumn{2}{|c|}{$\begin{array}{l}\text { Approximate monthly income per capita } \\
\text { in the household after retirement }\end{array}$} \\
\hline$<$ PLN 1000 & 5.9 \\
\hline PLN 1000-1500 & 52.9 \\
\hline PLN 1500-2000 & 32.4 \\
\hline$>$ PLN 2000 & 8.8 \\
\hline
\end{tabular}

CRU 10/0001637). Program participants were chosen with a purposeful selection method.

The group of women under research consisted mainly of widows (Table I) who had one or two children, who had completed high school education and who, after retiring, continued to work as economists, administration workers, teachers or nurses. The period of retirement ranged from 5 to 26 years. Half of the respondents' income per capita did not exceed PLN 1500.

The women took part in 4 months' nutrition education, from October to the end of January. The classes took place once a week for two lesson hours (45 minutes each) and each group had 36 and 32 participants. The program of the course comprised: basic knowledge about the digestive system, changes related to the age and resulting dietary recommendations; physiological role and requirement for basic nutrition ingredients, vitamins, micro and macro elements; the role of water in the digestive system and in general, water balance of the system. Many other subjects have been also discussed in the field of pathophysiology of older age, nutrition physiology, dietetics, proper methods of composing and preparing meals, role of sweeteners and other food additives etc. After completing studies of certain parts of educational material, the knowledge was verified (in written form or in practice e.g. proper composition of meals, choosing products with a low index and glycemic load, being skilled in "reading" labels etc.).

In the second week of the course, based on analysis of menus obtained using the ongoing noting method, feeding behavior was corrected, which consisted of standardization of time, amount and kind of consumed meals, with an explanation of a beneficiary influence of these changes on the organism. Next, recommendations have been introduced one by one and they were connected with currently discussed issues and individual requirements. In general, these recommendations concerned the amount of each nutritious ingredient, thus in line with the applicable standards: protein $0.9 \mathrm{~g} / \mathrm{kg}$ of current body mass of which $\pm 30 \%$ was animal protein; fats - for women with second and third degree obesity, individually not more than $25 \%$ but not less than $22 \%$, and for women with proper body mass or small overweight - $30 \%$ but not less than $28 \%$ of energy value of the daily food ration; carbohydrates $55-60 \%$ of energy value of the daily food ration.

All recommendations, taking into consideration physiology of nutrition and individual requirements, were also in compliance with nutrition standards for people in Poland [8].

Information about the nutrition methods was collected twice. The examined women, after proper education took notes themselves about the time, kind, and amount of food consumed on 3 (24-hour) randomly selected days of the week, including one at the weekend. Written data were completed during individual conversations 
with each of the participants. Menus (204 menus of 68 people from 3 days) came from the first days of October and - after the diet correction and implementation of the basic rules - from the end of January.

The size of portions was assessed with the help of the "Photo Album of products and dishes" [9]. Collected data were processed by a computer program Diet 5D İŻ̇. In the whole day, food rations (DFR) of each day consumption of ingredients was calculated and then average consumption of 3 days, which after taking the loss into consideration, was compared with nutrition standards for this age group of women with low physical activity (PAL 1.4) [8].

Body content was determined twice, before and after completing the education with a bio-impedance method (Bioelectrical Impedance Analysis - BIA) with the use of tetra polar, in the contralateral system (configuration hand-leg), of Bodystat ${ }^{\circledR} 1500$ MDD apparatus, made by Bodystat Ltd., with Body Manager CE 0120 software, using the regression equations for determining body content of elderly people [10]. The following was determined: the content of fat mass (FM), content of fat-free body mass (FFM) and total content of water (total body water - TBW).

The research was conducted on people lying flat, in the conditions of physical comfort and peace of mind, the ambient temperature was $21^{\circ} \mathrm{C}$, taking into account all producer's recommendations about the accuracy of conducted measurements, which was the cause why only 35 people out of 68 could be the subject for analysis of the achieved data.

Body mass was measured by legalized and standardized medical scales RADWAG WPT 200.0, once a week, on the day of the course, always keeping the same requirements of weighing, more to keep motivation for compliance than for evaluation. However, the anthropometric measurements being the subject of substantive analysis were taken at the beginning and after completing the education, during morning hours, in the nurse room of the Association of Third Age University and comprised: body mass without shoes in light outer clothes, using legalized and standardized medical scales RADWAG WPT - 200.0 accuracy to $0.1 \mathrm{~kg}$; body height measured in the Frankfurt plane horizontally with mobile stadiometer SECA 215, accuracy to $1 \mathrm{~mm}$; waist circumference measured half way between the bottom edge of costal arch and upper pectin of the iliac bone, in the conditions of short apnea with Gulick tape, accuracy to $1 \mathrm{~mm}$ and hips circumference measured in the place of the biggest circumference of buttocks below the iliac ala with the anthropometric Gulick tape, accuracy to $1 \mathrm{~mm}$.

The value of BMI was calculated according to the formula: body mass $[\mathrm{kg}] /$ height $\left[\mathrm{m}^{2}\right]$. Waist-to-hip ratio (WHR) was calculated according to the formula: waist circumference $[\mathrm{cm}] /$ hip ratio $[\mathrm{cm}]$ and waist-to-height ratio (WHtR) was calculated according to the formula: waist circumference $[\mathrm{cm}] /$ height $[\mathrm{cm}]$. For better illustration of nutritional behavior impact on location of the lost fat tissue, the absolute value of waist circumference (WC) was given, which is now more recommended in the evaluation of the cardiovascular disease risk than the WHR index.

In the course of education, participants led their customary lifestyle, unchanged especially as to physical activity (declared in individually conducted interviews), which was connected not only to age, existing overweight or obesity, but also, for many women, lack of certain habits and according to the participants "not a nice season".

The achieved results, after checking the normality of distribution, were statistically processed using statistical computer software Statistica ${ }^{\oplus} 9.0$, Student's $t$-test with the method of connected variables at the level of relevance $p \leq 0.05 ; 0.01$.

\section{Results}

It was noted that the average energy value of daily food rations before diet correction was, especially in women with proper weight, definitely too low in relation to that recommended by standards [8]. It was accompanied by too high consumption of animal protein, sucrose, fats in general, including saturated fats (Table II). These irregularities were reflected in the percentage of energy coming from basic nutritious ingredients (Table III). After correction of the diet and completing education, an increase, which was slight on average but important individually, in diet energy value, a decrease in fats in general, including saturated fats with a simultaneous increase in unsaturated fats and complex carbohydrates were noted. The changes introduced successively resulted also in a favorable increase in vitamins, minerals and liquids consumption. These changes were the effect of reciprocal changes in proportions of basic nutritious ingredients and changes in the number, kind and sources of nutritious ingredients consumed. The increase in consumption of cereals, fermented milk drinks, potatoes, fruit and vegetables with vitamin C, with beta-carotene and others and also seeds of legumes was statistically established. However, a statistically significant decrease was observed in consumption of meat and cold meats, sugar and sweets (Table IV).

During 4 months of education, a very individual decrease in body mass of participants was observed, which was reflected in the change of BMI, WC, WHR and WHtR values in the whole group of women under research (68 women) (Table $V$ ) and in the group under research for body composition (35 women) (Table VI).

Body content of women under research also changed. The percentage of fat in the body decreased, which was accompanied by a slight increase in percent- 
Tab. II. Energy value and basic nutrient levels in daily food rations of women before and after the nutrition awareness course ( $\bar{x} \pm S D, n=204$ menus)

\begin{tabular}{|c|c|c|}
\hline Components & Before education & After education \\
\hline Energy [kJ]; [kcal] & $\begin{array}{c}6732 \pm 2028 \\
1683 \pm 532\end{array}$ & $\begin{array}{l}7160 \pm 748 \\
1790 \pm 187\end{array}$ \\
\hline Total protein [g]: & $72.8 \pm 16.1$ & $70.1 \pm 15.3$ \\
\hline Animal protein & $47.2 \pm 15.6$ & $30.7 \pm 10.1^{* *}$ \\
\hline Plant protein & $25.6 \pm 7.5$ & $39.4 \pm 8.9^{\star *}$ \\
\hline Total carbohydrates [g]: & $185.0 \pm 54.2$ & $238.1 \pm 39.4^{\star}$ \\
\hline Starch & $145.8 \pm 59.6$ & $210.8 \pm 32.1^{\star *}$ \\
\hline Sucrose & $39.2 \pm 18.8$ & $27.3 \pm 5.2^{*}$ \\
\hline Dietary fiber & $18.8 \pm 8.3$ & $27.3 \pm 13.1^{\star *}$ \\
\hline Total fat [g]: & $72.4 \pm 23.6$ & $61.9 \pm 12.6^{*}$ \\
\hline Saturated fatty acids & $51.3 \pm 20.5$ & $30.1 \pm 14.9^{\star *}$ \\
\hline $\begin{array}{l}\text { Unsaturated fatty } \\
\text { acids }\end{array}$ & $21.1 \pm 18.9$ & $31.8 \pm 8.3^{*}$ \\
\hline Cholesterol [mg] & $283.7 \pm 118.4$ & $198.4 \pm 78.5^{*}$ \\
\hline \multicolumn{3}{|l|}{ Vitamins: } \\
\hline Retinol $[\mu \mathrm{g}]$ & $263.7 \pm 107.3$ & $275.4 \pm 69.4$ \\
\hline$\beta$-carotene $[\mathrm{mg}]$ & $3.72 \pm 3.12$ & $5.87 \pm 1.42^{*}$ \\
\hline Vitamin E [mg] & $9.1 \pm 5.0$ & $12.9 \pm 2.1^{*}$ \\
\hline Vitamin $D[\mu g]$ & $3.95 \pm 2.87$ & $7.28 \pm 2.1^{*}$ \\
\hline Vitamin C [mg] & $65.6 \pm 41.1$ & $82.4 \pm 21.9^{*}$ \\
\hline Vitamin $B_{6}[\mathrm{mg}]$ & $1.21 \pm 0.41$ & $1.64 \pm 0.39^{*}$ \\
\hline Vitamin $B_{12}[\mu \mathrm{g}]$ & $2.91 \pm 0.37$ & $2.56 \pm 0.12$ \\
\hline \multicolumn{3}{|l|}{ Mineral components: } \\
\hline Calcium [mg] & $560.0 \pm 350.0$ & $810.0 \pm 301.0^{\star}$ \\
\hline Magnesium [mg] & $216.4 \pm 77.5$ & $312.6 \pm 55.4^{\star}$ \\
\hline Zinc $[\mathrm{mg}]$ & $8.98 \pm 2.14$ & $8.32 \pm 2.71$ \\
\hline Sodium [mg] & $1912.0 \pm 682.0$ & $1428.0 \pm 241.0^{*}$ \\
\hline Potassium [mg] & $2938.0 \pm 847.0$ & $3652.0 \pm 471.0^{*}$ \\
\hline Liquids [ml] & $1060 \pm 230$ & $1590 \pm 110^{\star *}$ \\
\hline
\end{tabular}

age of fat-free body mass and water content (Table VII). In the absolute numbers, a significant decrease in fat content in bodies of women under research, which was accompanied by a slight increase in fat-free body mass and water content, was noted.

\section{Discussion}

Analysis of research results concerning evaluation of impact of four-month pro-health nutrition education of elderly women showed a number of beneficial changes in the way of nutrition. Generally these changes included improvement of the diet energy value and a share of energy coming from basic nutritious ingredients; decrease in meat and cold meats consumption replaced by dairy products and seeds of legumes; increase in consumption of unprocessed complex carbohydrates; replacement of some saturated fats by unsaturated fats; increase in consumption of fruit and vegetables, which was reflected in the increase of vitamins, mineral ingredients and fiber consumption. Liquids consumption also significantly increased. Analysis of other factors determining the consumption of groups of products chosen by women was also described by other authors [11-14].

The results achieved due to conducted education and diet correction, changes in the way of nutrition were the cause of a decrease (varying on a case-bycase basis) in body mass in women under research. It has found its reflection in changes of BMI, WC, WHR and WHtR. These changes indicated not only body mass and fat decrease, but could also indicate the improvement of the hormone metabolic status of the organism.

It has been shown in numerous researches that these values positively correlate with glycaemia wherein with glycaemia, after sucrose loading, the correlation with the value of BMI and WHtR indicators [15] is the strongest. Insulin secretion also changes in proportion not only to sucrose concentration changes in blood but also to BMI value changes, and its removal from the circulation by the liver negatively correlates with WHR $[4,16,17]$.

Analyzing the degree of changes of examined indicators in the group of 35 women whose body content was analyzed, it was ascertained that the highest decrease was observed for WC - on average by $7.5 \%$, next

Tab. III. Percentage of protein, carbohydrates, and lipids in the total energy content of daily food rations of women before and after the nutrition awareness course $(n=204$ menus)

\begin{tabular}{lccr}
\hline Index & Before education & After education & Reference \\
\hline Protein & 17.4 & 15.6 & $10-15$ \\
\hline Carbohydrates & 43.9 & 53.4 & $55-75$ \\
\hline Fat & 38.7 & 31.0 & $15-30$ \\
\hline Saturated & & 15.0 & DRV not determined \\
\hline Unsaturated $^{1}$ & 27.5 & 16.0 & DRV not determined
\end{tabular}


Tab. IV. Consumption of selected groups of products by women before and after the nutrition awareness course $(\bar{x} \pm S D$, $n=204)$

\begin{tabular}{|c|c|c|}
\hline Component & Before education & After education \\
\hline Cereals [g] ${ }^{1)}$ & $197.1 \pm 85.1$ & $287.1 \pm 60.2^{*}$ \\
\hline Dairy products $[g]^{2)}$ & $181.0 \pm 112.0$ & $620.0 \pm 52.0^{\star *}$ \\
\hline Eggs [g] & $18.0 \pm 12.0$ & $21.0 \pm 6.0$ \\
\hline Meat and sausages $[\mathrm{g}]^{3)}$ & $180.0 \pm 514$ & $55.0 \pm 20.5^{\star *}$ \\
\hline Butter and cream $[g]^{4)}$ & $12.0 \pm 14.0$ & $15.5 \pm 6.0$ \\
\hline Other fats [g] & $22.0 \pm 15.0$ & $31.8 \pm 8.0^{*}$ \\
\hline Potatoes [g] & $51.0 \pm 52.0$ & $69.0 \pm 35.0$ \\
\hline $\begin{array}{l}\text { Vitamin C-containing } \\
\text { fruit and vegetables [g] }\end{array}$ & $134.0 \pm 86.0$ & $158.0 \pm 25.0$ \\
\hline $\begin{array}{l}\text { Beta-carotene-rich fruit } \\
\text { and vegetables }[\mathrm{g}]\end{array}$ & $78.0 \pm 52.5$ & $123.0 \pm 32.5^{*}$ \\
\hline $\begin{array}{l}\text { Other fruit and vegeta- } \\
\text { bles [g] }\end{array}$ & $182.0 \pm 21.3$ & $348.0 \pm 41.0^{* *}$ \\
\hline Pulses [g] & $0.7 \pm 1.2$ & $28.3 \pm 5.0^{\star *}$ \\
\hline Sugar and sweets $[\mathrm{g}]^{5)}$ & $39.2 \pm 18.8$ & $27.3 \pm 6.2^{*}$ \\
\hline
\end{tabular}

WHtR - on average by $6.6 \%, \mathrm{BMI}-$ by $5 \%$ and WHR by $3.5 \%$. The degree of these changes was smaller by $30 \%$ than the changes observed in women aged $48-58$, which were the subject of similar pro-health nutrition education [5]. It might suggest that in the older age, proper diet correction and change of nutrition habits gives measurable and pro-health effects but to a smaller degree. This evaluation is not entirely true because it was ascertained that older women adopt pro-health
Tab. V. Changes in body weight, body mass index (BMI), waist circumference (WC), waist-to-hip ratio (WHR) and waistto-height ratio (WHtR) of women exposed to a 4-month-long health-enhancing nutrition awareness course $(\bar{x} \pm S D$, Min, Max, $n=68$ )

\begin{tabular}{lcc}
\hline Index & Before education & After education \\
\hline Body weight loss $[\mathrm{kg}]$ & & $1.6-9.8$ \\
& & $2.98 \pm 2.05$ \\
\hline BMI $\left[\mathrm{kg} / \mathrm{m}^{2}\right]$ & $24.1-44.5$ & $23.8-39.9$ \\
& $31.7 \pm 4.3$ & $30.2 \pm 3.7$ \\
\hline WC $[\mathrm{cm}]$ & $79.0-127.0$ & $78.0-121.0$ \\
& $101.5 \pm 10.7$ & $96.1 \pm 10.1$ \\
\hline WHR $[\mathrm{cm} / \mathrm{cm}]$ & $0.75-1.01$ & $0.75-0.98$ \\
& $0.89 \pm 0.06$ & $0.86 \pm 0.06$ \\
\hline WHtR $[\mathrm{cm} / \mathrm{cm}]$ & $0.50-0.79$ & $0.49-0.74$ \\
& $0.65 \pm 0.09$ & $0.61 \pm 0.07$ \\
\hline
\end{tabular}

Tab. VI. Changes in body weight, body mass index (BMI), waist circumference (WC), waist-to-hip ratio (WHR) and waist-toheight ratio (WHtR) of women exposed to a 4-month-long health-enhancing nutrition awareness course $(\bar{x} \pm S D$, Min, Max, $n=35$ )

\begin{tabular}{lcc}
\hline Index & Before education & After education \\
\hline Body weight loss $[\mathrm{kg}]$ & & $1.6-5.8$ \\
& & $2.8 \pm 1.6$ \\
\hline BMI $\left[\mathrm{kg} / \mathrm{m}^{2}\right]$ & $24.2-42.2$ & $24.1-39.8$ \\
& $32.2 \pm 4.6$ & $30.6 \pm 3.6$ \\
\hline WC $[\mathrm{cm}]$ & $79.0-125.0$ & $78.0-119.0$ \\
& $102.9 \pm 10.8$ & $95.6 \pm 9.3$ \\
\hline WHR $[\mathrm{cm} / \mathrm{cm}]$ & $0.75-1.01$ & $0.75-0.97$ \\
& $0.88 \pm 0.08$ & $0.85 \pm 0.09$ \\
\hline WHtR $[\mathrm{cm} / \mathrm{cm}]$ & $0.51-0.78$ & $0.49-0.73$ \\
& $0.64 \pm 0.08$ & $0.60 \pm 0.06$ \\
\hline
\end{tabular}

Tab. VII. Effects of health-promoting nutritional education and changed dietary habits on composition of the body $(\bar{x} \pm$ SD, $n=35)$

\begin{tabular}{|c|c|c|c|}
\hline Index & Before education & After education & Difference \\
\hline Body weight loss $[\mathrm{kg}]$ & & & $\begin{array}{c}1.6-5.8 \\
2.8 \pm 1.6\end{array}$ \\
\hline Fat content [\%] & $55.4 \pm 7.4$ & $52.8 \pm 6.1$ & \\
\hline Fat content [kg] & $44.1 \pm 10.8$ & $40.6 \pm 8.5^{*}$ & $-3.5 \pm 1.2$ \\
\hline Min-Max & $25.8-62.2$ & $24.6-56.2$ & \\
\hline Fat-free body weight content [\%] & $42.7 \pm 5.2$ & $45.1 \pm 4.9$ & \\
\hline Fat-free body weight content $[\mathrm{kg}]$ & $34.1 \pm 3.6$ & $34.6 \pm 3.2$ & $+0.53 \pm 0.18$ \\
\hline Min-Max & $28.8-40.1$ & $28.4-40.7$ & \\
\hline Water content [\%] & $46.3 \pm 4.9$ & $48.3 \pm 4.6$ & \\
\hline Water content $[\mathrm{kg}]$ & $36.9 \pm 3.6$ & $37.1 \pm 3.5$ & $+0.17 \pm 0.02$ \\
\hline Min-Max & $29.8-43.8$ & $31.7-43.9$ & \\
\hline
\end{tabular}


nutrition recommendations to a lesser degree, arguing the fact with possibility of taking proper medicines.

A change of waist circumference (WC) seems to be interesting and important from a medical point of view as noticed among older women under research. This could be related not only to the decrease in their body mass. It has been shown in fact that the body mass reduction with the so called "standard slimming" consisting of the correction of energy value of the diet causes first of all loss of subcutaneous fat tissue, especially the one located on lower limbs, in the axillary and hips region. With the lack of such changes in the waist circumference, this translates to no change or increase in the WHR and WHtR [18].

Taking into consideration the results of author's earlier research [6], the results of which show that in such diet correction, a higher loss of visceral fat tissue compared to subcutaneous tissue could be observed, the effect observed in the conducted research had to result in organism metabolism improvement [19]. It could also be supported by normalization of insulin and cortisol concentrations in blood observed in this type of diet correction [5], which normalization is responsible, among others, for fat tissue accumulation and location [20].

While analyzing the body content before diet correction it was ascertained that in $77 \%$ of women under research, the amount of fat in the body, important not only to assess the risk of such metabolic disorders as insulin resistance or dyslipidemia $[19,21]$ but also diseases such as vessels atherosclerosis, arterial hypertension and other [22], was much higher than recommended standards for this age group (22-31\%). Even in women whose BMI was 24.9-29.9 (33\% of examined women) defined as recommended standards for elderly people [23], fat content was from 25.8 to $33.7 \mathrm{~kg}$, which was from 39.2 to $52.7 \%$ of fat tissue in the body.

However analysis of the fat-free body mass, informing about the general content of muscular tissue, which amount, especially in older people, is the base of reference for biochemical and physiological indexes of organism functioning, showed that on average its amount was not even half the mass of body of the examined women. In $38 \%$ of the examined women, the content of fat-free body mass was even lower and amounted to 31.6 to $46.6 \%$, while the content recommended for the age and sex is $69-78 \%$.

The percentage of water content in the organism was also lower than the recommended level of $50-60 \%$. However it should be noted that in $45 \%$ of the examined women, the water content in the body was close to the lower limit of the standard. The rest of the women had the content of water in the body ranging between 39.6 and $43 \%$. This difference of water content in the body of the examined people might be connected, among others, with different content of fat tissue, which is the "storage" of water.
The changes taking place during 4 months' education as to the methods of nutrition had a positive impact on body content, however the loss of body mass was the most expected by women under research. And despite showing that in many of them the amount of fat tissue reduction was bigger than body mass loss they were not entirely satisfied with the change. A similar effect of seeing one's own body through the prism of body mass has been described by other authors [24].

It was noted that the absolute loss of fat tissue, on average $3.5 \pm 1.2 \mathrm{~kg}$, was higher than the average body mass loss. It was the effect of an increase in fat-free body mass and water in some women.

The changes made to the way of nutrition also influenced the percentage of fat-free body mass, which taking into consideration a lower amount of fat is an obvious phenomenon. The effect of keeping the absolute amount of fat free-body mass on an almost unchanged level seems more important. In the group under research in only about $15 \%$ of women, the body mass loss observed was also connected with a slight loss of fat-free body mass. In $76 \%$ of women under research, after 4 months of proper nutrition behavior, the absolute content of fat-free body mass increased on average by $0.87 \mathrm{~kg}$. And yet, the loss of fat-free body mass is one of frequent effects accompanying conducted slimming process. It was also shown that slimming, especially uncontrolled, might stimulate lipogenesis and deposition of energy substrates and the observed loss of body mass is then connected first of all with the loss of fat-free body mass and water [25].

It has been shown that physical inactivity has a negative effect on the nutritional status and body composition [26]. In the course of conducted classes, participants led a normal life that was unchanged, especially as regards physical activity, so the cause of this phenomenon cannot be sought in the influence of physical effort on the size of muscle mass. It seems that one of the causes of the phenomenon could be connected with diet correction and a decrease in the fat influence on amino acids and proteins metabolism [27]. It was shown that even with the decreased muscle mass this influence is not lower in the liver [28].

It also seems interesting, from a physiological point of view, that in the conducted research, an increase in water content in the bodies of some of the examined women was observed. Thanks to its role and physical-chemical properties and representing the highest percentage of the body, water is known as one of the most important ingredients of the organism. The examination conducted after four months showed that the $38 \%$ content of water in the organisms of the examined women has increased, but has not reached the lower limit of the standard which for this age group is $50 \%$. In $50 \%$ of examined women it did not change and in $12 \%$ it slightly decreased. The achieved effect is even more 
interesting taking into consideration the average fat mass loss of $3.5 \mathrm{~kg}$ including its content of about $10 \%$ of water, which loss should be observed in the course of the experiment of about 0.35 I on average.

The observed effect might have been connected with the detected, significantly higher consumption of potassium. It has been already demonstrated that with the increase in potassium consumption we can observe a decrease in sodium absorption in the renal tubules and on the other hand, a decrease in excretion of calcium with urine [29]. The mechanism of this influence is believed to be the cause of normalization of blood arterial pressure as observed in this experiment as well. In addition, potassium as an intracellular ion, in order to keep osmotic balance favored water absorption into cells governing this pressure, especially muscles improving their hydration.

Another cause of the observed phenomenon might have been found in this kind of studies, namely a decrease in cortisol concentration [3], suppressing among others secretion of vasopressin, which increases reversible resorption of water in kidneys.

When evaluating all the changes taking place in body content of the examined women it should be noted that the diet correction aiming first of all at improvement of the way of nutrition and state of health, had also a beneficiary impact on body mass reduction and its content. While observing the loss of fat tissue, it favored retaining or even increasing fat-free body mass and water content in the organism. The effects of changes of the nutritional behavior favored maintenance of physical endurance and improvement of well-being despite the effort which was needed to decide to take part in education and changes in the methods of nutrition.

The participants have also reported positive effects of changes in nutritional behavior and ways of nutrition: improvement of well-being, decrease or normalization of blood pressure certified by a doctor, decrease in heartburn symptoms or heartburn resolution, defecation normalization, sleep improvement, reduction of morning stiffness, improvement of humidity of nasal and mouth mucous membranes and many other often individual, but always personally important changes. It seems that general relief of the body among others by regulating meal times, lowered animal protein and saturated fats consumption and increased consumption of liquids, mainly in the form of water, fruit and vegetables being the source of biologically active ingredients playing key roles in the organism must have added up to better organism functioning.

Summarizing we can say that the changes of diet and nutrition methods in very basic but individually different terms, also in the elderly age, may result in improvement of well-being, health and a beneficial decrease in fat tissue including visceral tissue. However, it should be added that in the period of life during which good health seems to be the priority, the main problem still lies in convincing women to change their nutrition behaviors and that at this age looks are the strongest factor motivating the activity in this respect.

Despite this experiment was conducted on a small group of women and its results should not be generalized, it seems that such pro-health education can and should be applied in practice as one of the elements of care of the seniors.

\section{Conclusions}

Upon analysis of the achieved results we can state that the four months' pro-health nutrition education of women in the elderly age had an influence on changing the improper nutrition habits and on improving body functioning and well-being of women under research and the following was observed:

1) slow and individually different body mass loss, which was accompanied by a decrease in BMI, WC, WHR and WHtR,

2) body content changes - not only in reducing the fat percentage and increasing fat-free body mass and water, but a real decrease in fat content in the body, especially visceral fat, with lack of significant changes of fat-free body mass and water.

\section{Acknowledgements}

The authors would like to thank the Department of Health and Social Policy of the City of Szczecin, Poland, for the co-financing of research.

\section{Disclosure}

Authors report no conflict of interest.

\section{References}

1. Ferrara CM, Goldberg AP, Nicklas BJ, et al. Sex differences in insulin action and body fat distribution in overweight and obese middle-aged older men and women. Appl Physiol Nutr Metab 2008; 33: 784-790.

2. Pabis $M$, Babik $A$. The most frequent problems of the elderly based on analysis of "geriatric syndromes". Med Rodz 2007; 3: 62-65.

3. Jastrzębska-Mierzyńska M, Ostrowska L, Razak H, et al. The impact of bariatric surgery on nutritional status of patients. Videosurgery Miniinv 2015; 10: 115-124

4. Friedrich M. Effects of health-promoting nutritional education and change in dietary habits on visceral fatty tissue contents and on concentrations of insulin and cortisol in menopausal women. Pol J Food Nutr Sci 2005; 1: 91-96.

5. Friedrich M. Effects of diet modification and the resultant body weight loss on body composition in obese menopausal women. Pol J Food Nutr Sci 2007; 4: 503-508.

6. Friedrich M. Dietary modification of body composition and fat tissue distribution in obese menopausal women. Przeg Lek 2007; 64: 1-5.

7. Friedrich M, Goluch-Koniuszy Z. Evaluation of impact of Health-promoting education and resultant changes in nutritional behaviors on 
values of anthropometric parameters and carbohydrate-lipid metabolism markers in women aged 65-85 years. Probl Hig Epidemiol 2014; 95: 934-940.

8. Jarosz M. Nutrition standards for the Polish population - amendment. PZWL, Warszawa 2012.

9. Szponar L, Wolnicka A, Rychlik E. Album of Food Rations, Products and Dishes. National Food and Nutrition Institute, Warszawa 2002.

10. Deurenberg P. Assessment of body composition by bioelectrical impedance in a population aged $>60$ y. Am J Clin Nutr 1990; 51: 3-6.

11. Gacek M. Selected individual differences as predictors of milk product consumption in a group of perimenopausal women in the light of health hazards. Prz Menopauzalny 2013; 17: 300-306.

12. Gacek M. Selected individual determinants of cereal, fruit and vegetable consumption among menopausal women in view of potential health risks. Prz Menopauzalny 2013; 17: 385-391.

13. Malara M, Hübner-Woźniak E, Lewandowska I. Assessment of intake and nutritional status of vitamin B1, B2, and B6 in men and women with different physical activity levels. Biol Sport 2013; 30: 117-123.

14. Woźniak-Holecka J, Sobczyk K. Nutritional education in the primary prevention of osteoporosis in perimenopausal and postmenopausal women. Prz Menopauzalny 2014; 13: 56-63.

15. Report WHO 2008 - primary Health Care (Now More Than Ever).

16. Bener A, Yousafzai M, Darwish S, et al. Obesity index that predict metabolic syndrome: body mass index, waist circunference, waist hip ratio or waist height ratio. J Obes 2013; 2013: 269038.

17. Tousignant B, Faraj M, Conus F, et al. Body fat distribution modulates insulin sensitivity in post-menopausal overweight and obese women: a MONET study. Int J Obes 2008; 32: 1626-1632.

18. Laupez-Fontana CM, Sanchez-Villegas A, Martinez-Gonzales MA, et al. Daily physical activity and macronutrient distribution of low-calorie diets jointly affect body fat reduction obese women. Appl Physiol Nutr Metab 2009; 34: 595-602.

19. Giorgino F, Laviola L, Eriksson JW. Regional differences of insulin action in adipose tissue: insight from in vivo and in vitro studies. Acta Physiol Scand 2005; 183: 13-30.

20. Unger RH. Minireview: weapons of lean body mass destruction: the role of ectopic lipids in the metabolic syndrome. Endocrinology 2003; 144: 5159-5165.

21. Veilleux A, Caron-Jobin M, Noati S, et al. Visceral adipocyte hypertrophy is associated with dyslipidemia independent of body composition and fat distribution in women. Diabetes 2011; 60: 1504-1511.

22. Konig L, Merchant A, Poque J, et al. Waist circumference and waist-tohip ratio as predictors of cardiovascular events: meta-regression analysis of prospective studies. Euro Heart J 2007; 28: 850-856.

23. Mowè M. Men mat må de ha. In: Eldre i en brytningstid. Nord R, Eilertsen G, Bjerkreim T (eds.). Gylendal, Oslo 2005; 207-219.

24. Jafary F, Afzali L. Comparison of the effectiveness of four group therapies in improving the quality of life in menopausal women. Prz Menopauzalny 2013; 17: 194-201.

25. Shai I, Schwarzfuchs D, Henkin Y, et al. Weight loss with a low-carbohydrate, mediterranean or low-fat diets. N Engl J Med 2008; 359: 220-241.

26. Tomczak A, Bertrandt J, Kłos A. Physical fitness and nutritional status of polish ground force unit recruits. Biol Sport 2012; 29: 277-280.

27. Tessari P. Role of insulin in age-related changes in macronutrient metabolism. Europ J Clin Nutr 2000; 54: 126-130.

28. Beaufrere B, Morio B. Fat and protein redistribution with ageing: metabolic considerations. J Clin Nutr 2000; 54: 48-53.

29. Morris RC, Schmidlin O, Frassetto LA. Relationship and interaction between sodium and potassium. J Am Coll Nutr 2006; 25: 262-270. 